
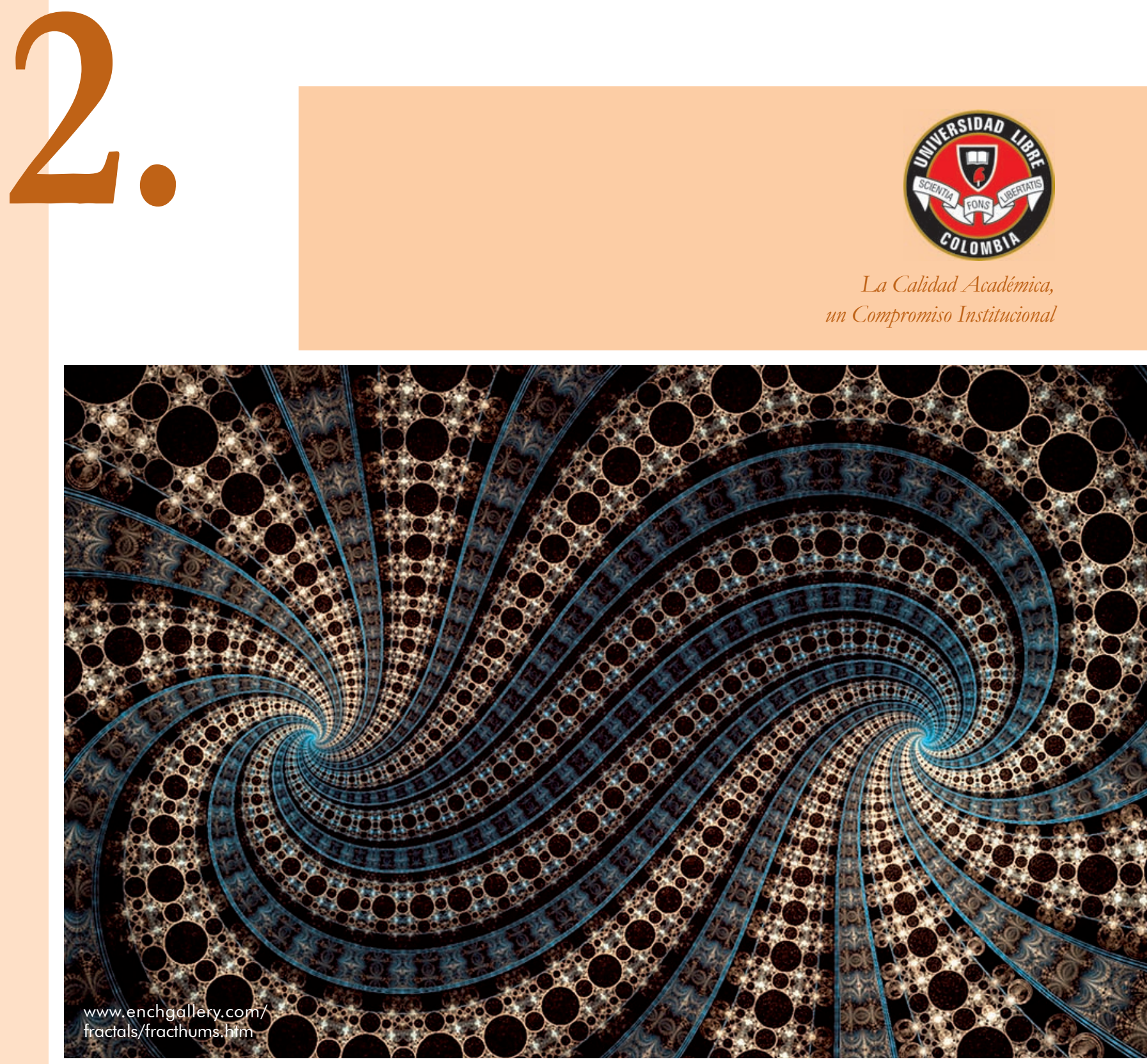

Álvarez S., Yolanda; Díaz M., Rubén D. y Saiz, Jorge E. (2012). Empresas de familia rurales, relaciones de género, relaciones de poder. Caso Lenguazaque, Cundinamarca.

Criterio Libre, 10 (17)

53-72

ISSN 1900-0642
Empresas de familia rurales, relaciones de género, relaciones de poder. Caso Lenguazaque, Cundinamarca Yolanda Álvarez Sáncbez • Rubén Darío Díaz Mateus • Jorge Enrique Saiz 


\section{EMPRESAS DE FAMILIA RURALES, RELACIONES DE GÉNERO, RELACIONES DE PODER. CASO LENGUAZAQUE, CUNDINAMARCA*}

RURAL FAMILY SMALL SCALED COMPANIES, GENDER AND POWER RELATIONSHIPS. LENGUAZAQUE, CUNDINAMARCA CASE

EMPRESAS DE FAMÍLIA RURAIS, RELAÇÕES DE GÊNERO, RELAÇÕES DE PODER. CASO

LENGUAZAQUE, CUNDINAMARCA

LES ENTREPRISES FAMILIALES RURALES, LES RELATIONS ENTRE LES SEXES, LES RELATIONS DE POUVOIR. CAS LENGUAZAQUE, CUNDINAMARCA-COLOMBIE

YOLANDA ÁLVAREZ SÁNCHEZ
RUBEEN DARÍO DÍAZ MATEUS
JORGE ENRIQUE SAIZ

Artículo de investigación correspondiente al proceso que han venido desarrollando sus autores en el marco del proyecto de investigación "Propuesta de un modelo integral bajo el enfoque de sostenibilidad en la cadena productiva del sector lácteo" con el apoyo de la Facultad de Ciencias Administrativas y Contables de la Universidad de La Salle, Bogotá, Colombia.

Research Article by the authors of "Proposal for a Sustainable Dairy Industry Complete Model" project, with the support of the Administrative and Accounting Science Faculty, La Salle University, Bogotá, Colombia.

Artigo de pesquisa correspondente ao processo que vêm desenvolvendo seus autores dentro do projeto de pesquisa "Proposta de um modelo integral sob o enfoque de sustentabilidade na cadeia produtiva do setor lácteo" com o apoio da Faculdade de Ciências Administrativas e Contábeis da Universidade de La Salle, Bogotá, Colômbia.

Document de recherche dans le cadre du projet «Proposition pour un modèle intégré du point de vue de la durabilité dans la chaîne de production laitière», avec le soutien de la Faculté de Gestion et de la Comptabilité. Université de la Salle, Bogota, Colombie.

‡ Profesora investigadora de la Facultad de Ciencias Administrativas y Contables de la Universidad de La Salle, Bogotá, Colombia. Magíster en literatura hispanoamericana, candidata a doctora en gerencia de proyectos, de la Universidad Tecnológica de Panamá y la Universidad de Jaén, España. Grupo de Investigación DES-UNISALLE. yalvarez@ unisalle.edu.co.

Research professor, Administrative and Accounting Science Faculty, La Salle University, Bogotá, Colombia. Masters in Latinamerican Literature, Doctorate Candidate in Project Management from the Technological University, Panama and the Jaén University, Spain. Research group DES-UNISALLE. yalvarez@unisalle.edu.co.

Professora pesquisadora da Faculdade de Ciências Administrativas e Contábeis da Universidade de La Salle, Bogotá, Colômbia. Mestre em literatura hispanoamericana, candidata a doutora em gerência de projetos, da Universidade Tecnológica de Panamá e a Universidade de Jaén, Espanha. Grupo de Pesquisa DES-UNISALLE. yalvarez@unisalle. edu.co.

Professeur chercheur de la Faculté de Gestion et Comptabilité de I'Université de La Salle, Bogota, Colombie. Master en littérature américaine, candidat au doctorat en gestion de projet, I'Université technologique du Panama et de I'Université de Jaén, en Espagne. DESUNISALLE.yalvarez@unisalle.edu.co.

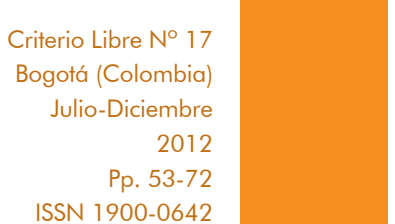




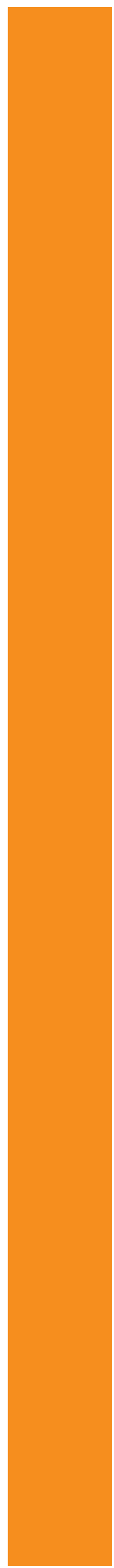

Fecha de recepción: marzo 30 de 2012

Fecha de aceptación: agosto 7 de 2012

Reception Date: March 302012

Acceptance Date: August 72012

Data de recepção: 30 de março de 2012

Data de aceitação: 7 de agosto de 2012

Reçu: Mars 30, 2012

Accepté: Août 7, 2012

\section{RESUMEN}

Se trabajó con la población rural, hombres y mujeres, del municipio de Lenguazaque; la investigación tuvo como objeto determinar las relaciones de género como relaciones de poder en las empresas familiares rurales. Se siguió un proceso metodológico tanto inductivo como deductivo. Fue inductivo en la medida en que se trabajó con la comunidad en el desarrollo de actividades que nos permitieron ir consolidando los resultados que aquí se presentan; fue deductivo, dado que se partió de fuentes teóricas que permitieron comprender la dinámica del sector rural y el comportamiento

$\S$ Economista, Universidad Pedagógica y Tecnológica de Colombia (UPTC), Bogotá, Colombia. Candidato a doctor en economía aplicada, de la Universidad de Santiago de Compostela (España). Especialista en planeación y gestión del desarrollo territorial, UPTC. Docente de la Facultad de Ciencias Administrativas y Contables. Grupo de Investigación DES-UNISALLE.rudiaz@unisalle.edu.co.

Economist, Pedagógica y Tecnológica University of Colombia (UPTC), Bogotá, Colombia. Doctorate Candidate in Applied Economics, Santiago de Compostela University (Spain). Planning and Land Development Management Specialist UPTC. Teacher, Administrative and Accounting Science Faculty.Research Group DES-UNISALLE. rudiaz@unisalle.edu.co.

Economista, Universidad Pedagógica e Tecnológica de Colombia (UPTC), Bogotá, Colômbia. Candidato a doutor em economia aplicada, da Universidade de Santiago de Compostela (Espanha). Especialista em planejamento e gestão do desenvolvimneto territorial, UPTC. Docente da Faculdade de Ciências Administrativas e Contábeis. Grupo de Pesquisa DES-UNISALLE.rudiaz@unisalle.edu.co.

Economiste, Université Pédagogique et technologique de Colombie (UPTC). Candidat au doctorat en économie appliquée à I'Université de Santiago de Compostela (Espagne). Spécialiste en planification et gestion du développement territorial, UPTC. Professeur de la Faculté de Gestion et Comptabilité. Groupe DES-UNISALLE. rudiaz@unisalle.edu.co.

* Economista de la Universidad Santo Tomás, Bogotá, Colombia. Magíster en ciencias económicas, Universidad Santo Tomás. Profesor investigador de la Facultad de Ciencias Administrativas y Contables, Universidad de La Salle, Bogotá. Grupo de Investigación DES-UNISALLE.jsaiz@unisalle.edu.co.

Economist, Universidad Santo Tomás, Bogotá, Colombia. Masters in Economic Science, Santo Tomás University. Research Professor, Administrative and Accounting Sciences Faculty, La Salle University, Bogotá. Research Group DES-UNISALLE. jsaiz@unisalle.edu.co.

Economista da Universidade Santo Tomás, Bogotá, Colômbia. Mestre em ciências econômicas, Universidade Santo Tomás. Professor pesquisador da Faculdade de Ciências Administrativas e Contábeis, Universidade de La Salle, Bogotá. Grupo de pesquisa DESUNISALLE.jsaiz@unisalle.edu.co.

Économiste. Master en sciences économiques, Université Santo Tomas Professeur chercheur de la Faculté de Gestion et Comptabilité de I'Université de La Salle, Bogota. DES-UNISALLE.jsaiz@unisalle.edu.co. 
que, en términos de relaciones, se da en el interior de este. Los resultados obtenidos del proceso están relacionados con la amplia participación de la mujer en el desarrollo de las actividades agrícolas y ganaderas, lo mismo que en las actividades del hogar; esto significa que las mujeres campesinas aportan, de manera dinámica y decidida, al bienestar de la familia y de la comunidad, hecho que no tiene gran reconocimiento tanto de la familia como de los distintos órganos del gobierno.

\section{PALABRAS CLAVE:}

Empresas de familia rurales, género, poder, capacidades humanas.

CLASIFICACIÓN JEL:

D21, D24, D29, D63.

\section{SUMMARY}

This study was made in cooperation with the male and female rural community of Lenguazaque, Department of Cundinamarca, with the objective of determining gender relationships as well as power relationships in rural family small scaled companies, following a methodological process both inductive and deductive. It was inductive because we developed activities with the community which enabled us to consolidate the present results. It was deductive because we considered theoretical sources to understand the dynamics of the rural world and its behavior in their relationships.

As a result we acknowledged the vast participation of women in the development of agricultural and home related activities. This means that rural women improve the wellbeing of families and community in a dynamic and resolute way not recognized by their families and/or the government.

Key words: Rural family companies, gender, power, human aptitude. JEL Classification: D21, D24, D29, D63.

Trabalhou-se com a população rural, homens e mulheres, do município de Lenguazaque; a pesquisa teve como objeto determinar as relações de gênero como relações de poder nas empresas familiares rurais. Seguiuse um processo metodológico tanto indutivo como dedutivo. Foi indutivo na medida em que trabalhou-se com a comunidade no desenvolvimento de atividades que nos permitiram ir consolidando os resultados que aqui apresentam-se; foi dedutivo, dado que partiu-se de fontes teóricas que permitiram comprender a dinâmica do setor rural e o comportamento que, em termos de relações, dá-se no interior deste. Os resultados obtidos do processo estão relacionados com a ampla participação da mulher no 


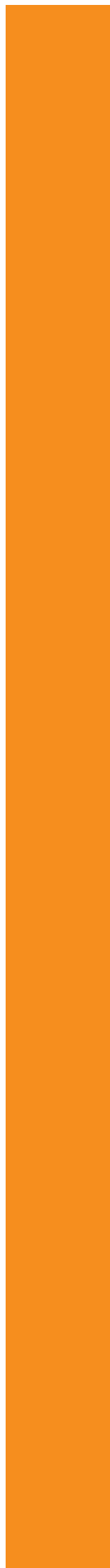

desenvolvimento das atividades agrícolas e pecuárias, o mesmo que nas atividades do lar; isto significa que as mulheres camponesas contribuem, de maneira dinâmica e decidida, ao bem estar da família e da comunidade, feito que não tem grande reconhecimento tanto da família como dos distintos órgãos do governo.

Palavras chave: Empresas de famílias rurais, gênero, poder, capacidades humanas. Classificação JEL: D21, D24, D29, D63.

\section{RÉSUMÉ}

Les auteurs ont travaillé avec les populations rurales, hommes et femmes, dans le canton Lenguazaque, la recherche a eu pour objectif, déterminer les relations de genre en tant que relations de pouvoir dans les entreprises familiales rurales. Une démarche méthodologique a été suivie à la fois inductive et déductive. Inductive dans la mesure où nous avons travaillé avec la communauté dans le développement des activités qui nous ont permis de consolider les résultats.

Déductive car il était sur les sources théoriques qui leurs ont permis de comprendre la dynamique du comportement en milieu rural et qui se produit à l'intérieur.

Les résultats du processus sont liés à une large participation des femmes dans le développement des activités agricoles, ainsi que dans les activités ménagères, ce qui signifie que les femmes rurales contribuent, et déterminent de manière dynamique, le bien-être familiale et de la communauté, ce qui n'est pas toujours reconnu à la fois ni par la famille ni par les divers organes de gouvernement.

Mots-clés: Entreprises familiales rurales, le sexe, le pouvoir, les capacités humaines. Classification JEL: D21, D24, D29, D63.

\section{- INTRODUCCIÓN}

El medio rural y la nueva ruralidad son definidos por Faraha y Pérez (2004), como "una entidad sicioeconómica y un espacio geográfico compuesto por un territorio, una población, un conjunto de asentamientos y un conjunto de instituciones públicas y privadas". Es un conjunto de regiones o zonas en las que se asientan pueblos, aldeas, pequeñas ciudades y centros regionales, espacios naturales y cultivados, y en donde se desarrolla una gran diversidad de actividades como la agricultura, la industria pequeña y mediana, el comercio, los servicios, la ganadería, la pesca, la minería, el turismo y la 
66

... definimos las empresas de familia rurales como el tipo de organización en la que confluyen personas que mantienen entre sí algún tipo de parentesco, ya sea este natural, de sangre (madre, padre, hijos, bermanos, hermanas, tías, primos) o legal (esposo, esposa, bijo). extracción de recursos naturales (Ceña, 1993, citado por Faraq y Pérez).

En este contexto, definimos las empresas de familia rurales como el tipo de organización en la que confluyen personas que mantienen entre sí algún tipo de parentesco, ya sea este natural, de sangre (madre, padre, hijos, hermanos, hermanas, tías, primos) o legal (esposo, esposa, hijo). Las empresas rurales en América Latina se caracterizan porque todos sus miembros participan en el desarrollo productivo de las mismas. Estas empresas se constituyen en un bien patrimonial que pasa de generación en generación -con los conflictos que la sucesión implica-, pues en ocasiones muchas de estas empresas de familia no alcanzan mayor grado de crecimiento, aunque muchas otras sí logran constituirse como verdaderos latifundios dispuestos tanto para las actividades agrícolas como ganaderas.

En las empresas de familia rurales toda la familia participa en el desarrollo y conservación de las mismas y no se establece una diferencia entre el concepto de familia y el concepto de empresa. Por esto, todas las actividades que realizan desde que se levantan, a las 4:00 a.m., hasta que se acuestan, a las 6:00 p.m., hacen parte de su quehacer diario como formas económicas de subsistencia; por supuesto, no hay cargos diferenciados, simplemente se guarda cierto respeto entre sus miembros que obedece a niveles de jerarquía -relaciones de poder- y edad: padre, madre, hermano mayor, etc.

Vale la pena señalar que hay empresas rurales legalmente constituidas que guardan plenamente el protocolo que exige la ley a nivel administrativo. En este artículo se está haciendo referencia a las actividades rurales en general, considerando la empresa de familia rural como una unidad productiva, constituida por el esposo, la esposa y los hijos y caracterizada, fundamentalmente, por minifundios; la ganadería y la agricultura son las principales formas de explotación de la tierra y mecanismos de subsistencia. Aunque a muchos campesinos no les interesa competir en 
el mercado con otros productores, sí les interesa el mercado en términos de precios, dado que la explotación de sus productos les garantiza una mejor calidad de vida para la familia.

Conviene resaltar que el trabajo más exigente en el sector rural recae en la mujer: las mujeres son madres, esposas y trabajadoras; ellas se dedican, junto con su esposo y con sus hijos cuando estos la acompañan, al trabajo de las fincas de donde obtienen los recursos necesarios para sobrevivir. Ellas, al igual que los hijos, rara vez reciben un pago en efectivo por el ejercicio de actividades que no les dejan tiempo para sí mismas, para ellas no están permitidas las actividades sociales (misas, entierros, visitas a vecinos por problemas con las fincas), ni los viajes al pueblo para realizar la comercialización de los productos; son los esposos quienes, generalmente, se ocupan de tales actividades, y en algunas familias la esposa solo acompaña al esposo pero no tiene poder decisorio.
En varias familias ya se observa que los esposos dejan a cargo de la esposa actividades como la agricultura o la ganadería para que ellos puedan trabajar en otras fincas por un jornal' como agricultores, cuidadores, o en la minería, actividad esta que, paradójicamente ${ }^{2}$, en América Latina y particularmente en Colombia está adquiriendo una importancia crucial en el crecimiento económico de muchas de sus regiones.

En este orden de ideas, el objetivo del presente estudio busca dar cuenta del tipo de relaciones que en las empresas de familia rurales se establecen; para ello se ha estructurado la propuesta, en primer lugar, con una fundamentación teórica desde el contexto de las empresas rurales y de lo que significan las relaciones tanto de género como de poder; en segundo lugar, se determinan las estrategias metodológicas seguidas en el estudio con la población rural del municipio de Lenguazaque para, finalmente, presentar los resultados, la discusión y las conclusiones.

\section{FUNDAMENTACIÓN TEÓRICA}

Los nuevos contextos de desarrollo han vuelto la mirada hacia lo rural considerando que allí puede encontrase la salida en la disminución de la pobreza y el hambre. En efecto, el informe sobre agricultura y desarrollo rural sostenible (2007) señala que "cada día hay mayor consenso en que las empresas rurales y la diversificación hacia actividades orientadas al mercado y que generen ingresos son un instrumento para mejorar los medios de vida y la seguridad alimentaria".

El documento hace referencia a seis aspectos que generalmente desconocemos y que conviene citar sobre las empresas de familia rurales:

"900 millones de personas o tres cuartas partes de las que padecen hambre y pobreza en el mundo viven en áreas rurales, donde las condiciones de trabajo suelen ser muy duras".

Los agricultores que combinan métodos agrícolas convencionales con empresas rurales innovadoras gozan de mayores ingresos y medios de vida más seguros que aquellos que se dedican a la agricultura tradicional o al trabajo asalariado.

El desarrollo de empresas domésticas es una estrategia muy promisoria para el aumento de ingresos justos y trabajo decente.

Las micro y pequeñas empresa son la mayor fuente de empleo en los países en desarrollo.

\footnotetext{
Pago que recibe un campesino por un día de trabajo.

2 Dado el esfuerzo que muchos gobiernos están haciendo por el cuidado y protección del medio ambiente, se está desarrollando este tipo de actividad que atenta contra los bienes más preciados del hombre: su vida y los recursos naturales.
} 
Entre la mitad y las tres cuartas partes de las personas que se ganan la vida o complementan sus ingresos en la micro o pequeña empresa son mujeres.

Considerando que de potenciarse el desarrollo de las empresas de familia rurales pudiera generarse una mejor calidad de vida para la población rural, es conveniente considerar qué aspectos caracterizan a dichas empresas (ver cuadro 1) y a qué riesgos se ven enfrentadas. Las empresas de familia rurales no solo tienen limitaciones de índole administrativa y financiera, sino que además los campesinos carecen de posibilidades de créditos para financiar sus ideas de negocio hasta que estas se puedan sostener por sí mismas; las mujeres tienen menor acceso a mejores oportunidades salariales y tienen que repartir su tiempo entre los quehaceres domésticos y la empresa; carecen de medios de comunicación eficientes y sistemas de carreteras adecuados, lo que impide que se pueda acceder a mejores mercados o que se generen redes comerciales con empresas urbanas (Tabla 1).

En cuanto al acceso de recursos no renovables (ver cuadro 2) los gobiernos deben proveer la infraestructura que permita que las empresas rurales puedan acceder tanto a recursos naturales como a recursos financieros, físicos, humanos y sociales. Esto es debido a que generalmente el desarrollo, sobre todo el económico, genera un gran impacto sobre el medio ambiente $y$, particularmente, sobre los recursos naturales que es necesario proteger y conservar; sin embargo, muchas veces los campesinos son indiferentes a ello (Tabla 2).

\section{Tabla 1. Caracterización de las empresas rurales.}

\begin{tabular}{|c|c|c|c|}
\hline $\begin{array}{l}\text { Características de las } \\
\text { empresas rurales }\end{array}$ & Diversificación & Incentivos y subsidios & Empresas rurales y género \\
\hline $\begin{array}{l}\text { Recursos limitados como } \\
\text { mano de obra, habilidades } \\
\text { y capital. }\end{array}$ & $\begin{array}{l}\text { El fomento de las empresas } \\
\text { rurales alienta a las fami- } \\
\text { lias campesinas a diversifi- } \\
\text { car su sistema de produc- } \\
\text { ción al introducir empresas } \\
\text { agrícolas y no agrícolas. }\end{array}$ & $\begin{array}{l}\text { Los mercados son imper- } \\
\text { fectos en muchos contex- } \\
\text { tos rurales y los incentivos } \\
\text { y subsidios son necesarios } \\
\text { para impulsar el desarro- } \\
\text { llo. }\end{array}$ & $\begin{array}{l}\text { El tiempo que las mujeres dedican } \\
\text { al trabajo doméstico por lo general } \\
\text { implica que dediquen menos tiempo } \\
\text { al desarrollo de la empresa. }\end{array}$ \\
\hline $\begin{array}{l}\text { Costos de transacción ele- } \\
\text { vados debido a sus peque- } \\
\text { ñas dimensiones, naturale- } \\
\text { za dispersa y a su lejanía. }\end{array}$ & $\begin{array}{l}\text { Lo anterior podría traer } \\
\text { como consecuencia: au- } \\
\text { mento en los costos de } \\
\text { producción; degradación } \\
\text { ambiental y/o impacto ne- } \\
\text { gativo en las relaciones de } \\
\text { género. }\end{array}$ & $\begin{array}{l}\text { Los subsidios deben apo- } \\
\text { yar la creación de capa- } \\
\text { cidades, las economías de } \\
\text { escala y la eficiencia del } \\
\text { mercadeo. }\end{array}$ & $\begin{array}{l}\text { Las mujeres suelen estar excluidas } \\
\text { de las oportunidades salariales de- } \\
\text { bido a normas culturales, marcos le- } \\
\text { gales, niveles de educación, limita- } \\
\text { ciones de tiempo y poder en la toma } \\
\text { de decisiones. }\end{array}$ \\
\hline $\begin{array}{l}\text { Riesgos comerciales prove- } \\
\text { nientes de desequilibrios de } \\
\text { poder respecto a grandes } \\
\text { compañías o de compra- } \\
\text { dores que pueden influir en } \\
\text { los términos, en las condi- } \\
\text { ciones y en los estándares } \\
\text { requeridos. }\end{array}$ & $\begin{array}{l}\text { Las empresas rurales tie- } \\
\text { nen el potencial de gene- } \\
\text { rar más ingresos que la } \\
\text { mano de obra asalariada, } \\
\text { pero requiere mayor inver- } \\
\text { sión de capital, mayores } \\
\text { riesgos y mano de obra } \\
\text { más intensiva. }\end{array}$ & $\begin{array}{l}\text { Los subsidios deben ir dis- } \\
\text { minuyendo a medida que } \\
\text { el mercado se va desarro- } \\
\text { llando. }\end{array}$ & $\begin{array}{l}\text { Las oportunidades empresariales } \\
\text { pueden dotar a las mujeres de inde- } \\
\text { pendencia, mayor respeto y estatus } \\
\text { social. Esto puede hacer que tengan } \\
\text { una mayor participación en la toma } \\
\text { de decisiones en su comunidad. }\end{array}$ \\
\hline $\begin{array}{l}\text { Limitada información debi- } \\
\text { do a la débil infraestructu- } \\
\text { ra de transporte y comuni- } \\
\text { caciones. }\end{array}$ & & & \\
\hline
\end{tabular}

Fuente: Elaboración propia con base en Agricultura y desarrollo rural sostenibles (ADRS), sumario de política. Las ADRS y las empresas rurales (2007). Documento en línea de ftp//ftp.fao.org/docrep/fao/010/ai120s/ai129s.pdf (recuperado el 12 de octubre de 2011 ). 
Tabla 2. Las empresas de familia rurales y el acceso a recursos.

\begin{tabular}{|c|c|c|c|c|}
\hline Recursos naturales & $\begin{array}{l}\text { Recursos } \\
\text { financieros }\end{array}$ & Recursos físicos & Recursos humanos & Recursos sociales \\
\hline \multirow[t]{2}{*}{$\begin{array}{l}\text { Poner en vigor una } \\
\text { legislación que per- } \\
\text { mita a las empresas } \\
\text { rurales usar la base } \\
\text { de recursos natura- } \\
\text { les de una manera } \\
\text { sostenible. }\end{array}$} & $\begin{array}{l}\text { Fomentar la crea- } \\
\text { ción de grupos de } \\
\text { ahorro para generar } \\
\text { capital y alentar la } \\
\text { autoconfianza en el } \\
\text { interior de los hoga- } \\
\text { res y de las comuni- } \\
\text { dades vulnerables. }\end{array}$ & $\begin{array}{l}\text { Desarrollar una in- } \\
\text { fraestructura rural } \\
\text { como caminos, sis- } \\
\text { temas de suministro } \\
\text { de agua y electri- } \\
\text { cidad y redes de } \\
\text { comunicación para } \\
\text { apoyar el desarrollo } \\
\text { de las empresas ru- } \\
\text { rales. }\end{array}$ & $\begin{array}{l}\text { Ofrecer capacita- } \\
\text { ción para el desa- } \\
\text { rrollo de habilidades } \\
\text { empresariales y de } \\
\text { gestión. }\end{array}$ & $\begin{array}{l}\text { Fomentar la creación de ca- } \\
\text { pital social mediante grupos } \\
\text { formales e informales; por } \\
\text { ejemplo, grupos de autoayu- } \\
\text { da, organizaciones de base } \\
\text { comunal, cooperativas, aso- } \\
\text { ciaciones campesinas o es- } \\
\text { cuelas de campo agrícolas. }\end{array}$ \\
\hline & $\begin{array}{l}\text { Garantizar que las } \\
\text { empresas rurales, en } \\
\text { especial las mane- } \\
\text { jadas por personas } \\
\text { de escasos recursos, } \\
\text { tengan acceso a } \\
\text { servicios financieros } \\
\text { adecuados para sa- } \\
\text { tisfacer sus necesi- } \\
\text { dades. }\end{array}$ & $\begin{array}{l}\text { Liberar a las mujeres } \\
\text { del tiempo que les } \\
\text { demanda las tareas } \\
\text { domésticas, a fin de } \\
\text { que puedan manejar } \\
\text { sus propias empre- } \\
\text { sas rurales. }\end{array}$ & $\begin{array}{l}\text { La capacitación } \\
\text { debe ser práctica y } \\
\text { estar basada en la } \\
\text { experiencia y orien- } \\
\text { tada a la resolución } \\
\text { de problemas, así } \\
\text { como simular situa- } \\
\text { ciones de la vida } \\
\text { real. }\end{array}$ & $\begin{array}{l}\text { Alentar a las mujeres para } \\
\text { que desarrollen mecanismos } \\
\text { tradicionales de solidaridad } \\
\text { grupal mediante actividades } \\
\text { en grupo. }\end{array}$ \\
\hline
\end{tabular}

Fuente: Elaboración propia con base en Agricultura y desarrollo rural sostenibles (ADRS), sumario de política. Las ADRS y las empresas rurales (2007). Documento en línea de ftp//ftp.fao.org/docrep/fao/010/ai120s/ai129s.pdf (recuperado el 12 de octubre de 2011 ).

\section{RELACIONES DE GÉNERO, RELACIONES DE PODER}

El tipo de relaciones que se llevan a cabo en las empresas de familia rurales no distan mucho de las urbanas dado que la desigualdad entre géneros hace parte de los paradigmas culturales que se están empezando a revaluar, por lo menos en teoría. Las mujeres campesinas, no obstante, son mucho más susceptibles a la discriminación y explotación; lo anterior se justifica desde la prevalencia cultural casi universal del hombre sobre la mujer, hasta la falta de oportunidades de desarrollo para ellas.

"La mujer juega un papel muy, muy importante dentro de la sociedad; y en la casa también, puesto que el hombre es el que pone un bien tangible dentro del hogar. La mujer un bien intangible que es el desarrollo de la familia, educar a sus hijos en valores, en moral, en costumbres; la mujer puede proyectar negocios pero para ello es necesario que tenga una capacitación y se aumente el nivel de confianza y de autoestima en cada una de ellas, para que en ciertos momentos sean capaces de tomar el liderazgo dentro del hogar. La mujer es emprendedora y se considera que es más emprendedora que el hombre y se debe respetar a la mujer de una forma más civilizada" (Mujer campesina del municipio de Lenguazaque).

En este orden de ideas, las mujeres, además de trabajar tiempo completo dado que comparten los quehaceres del hogar junto con el trabajo en su propia empresa, tienen menos oportunidades que les permitan educarse y conocer las múltiples opciones que ofrecen los gobiernos frente al desarrollo rural. Una mujer educada significa no solo tener mejores oportunidades de desarrollo para ella, sino mejor calidad de vida para su familia. Seguramente por el abandono en que 
${ }^{6}$ En el espacio social rural se consideran las relaciones de poder desde dos perspectivas: en el interior del hogar, como espacio intimo en donde el hombre, y en general toda su familia, ejerce relaciones de poder sobre la mujer y esta sobre sus bijos (microfísica del poder). muchos países tienen a la mujer rural, este sector no se ha aprovechado adecuadamente.

El estudio realizado por Faraq y Pérez (2004) caracteriza las actividades de las mujeres en Boyacá y Tumaco, por ejemplo, en tres tipos; en efecto, sostienen que las mujeres de estos contextos rurales se dedican a: a) actividades productivas, en estas incluyen las actividades que generan ingresos directos como las que contribuyen a la reproducción de las unidades domésticas; b) actividades reproductivas; c) actividades comunitarias como juntas de acción comunal, reuniones de los hijos en el colegio y/o en la escuela. Diríamos, de acuerdo con esto, que los hombres, a diferencia de las mujeres campesinas, solo se dedican a actividades productivas, en el sentido económico del término. Un equilibrio entre las actividades de unos y de otros podría traer un beneficio mayor para las familias y disminuir, en consecuencia, los índices de pobreza rural.

Si bien es cierto que en muchos países en desarrollo se están empezando a establecer programas que permitan el equilibrio entre equidad y sostenibilidad como ejes del desarrollo de las capacidades humanas ${ }^{3}$, muchos otros países están empezando a considerar el desarrollo solamente en términos económicos, y muchos otros aún no tienen la cobertura necesaria para llegar a los cientos de miles de mujeres campesinas en quienes la desigualdad también se hace notoria de acuerdo con el PNUD (2011), en aspectos como restricciones a la salud reproductiva y escasa participación en la toma de decisiones políticas nacionales y locales.

3 El desarrollo humano, según el PNUD (2011), trata de la expansión de libertades y capacidades de la gente para vivir una vida que valoren y que tienen razones para valorar. El desarrollo humano supone la expansión de la libertad de las personas para vivir una vida larga, saludable y creativa, perseguir los objetivos que consideren valorables y participar activamente en el desarrollo sostenible y equitativo del planeta que comparten. 
El ejercicio del poder, de acuerdo con Foucault (1991), se hace presente en la existencia de al menos dos sujetos actuantes, uno y otro; al confrontar sus acciones, podrían dar como resultado el consenso o la violencia. Este mismo autor señala que el ejercicio del poder sin libertad sería esclavitud; no obstante, tal afirmación pudiera debatirse si consideramos las implicaciones que tiene para una persona, mujer en este caso, la limitación de sus capacidades (Nussbaum, 2002). En tal sentido señala Nussbaum (2002) cómo "en muchos casos, el daño que las mujeres sufren en la familia asume una forma particular: la mujer es tratada no como un fin en sí misma, sino como un agregado o un instrumento de las necesidades de los otros, como una mera reproductora, cocinera, fregadora, lugar de descarga sexual, cuidadora, más que como una fuente de capacidad para elegir y perseguir metas y como una fuente de dignidad en sí misma" (p. 322).

"Las mujeres deberían planear sus actividades, de esta manera les quedaría más tiempo para ellas. Levantarse en la mañana y determinar lo que van a hacer durante el día y a partir de allí poder organizar sus actividades. Las mujeres solo se dedican a pensar con quién anda el esposo por motivo de los celos; por estar dedicada a qué hace el esposo, por eso no les alcanza el tiempo para sí mismas" (Campesino del municipio de Lenguazaque).
En el espacio social rural se consideran las relaciones de poder desde dos perspectivas: en el interior del hogar, como espacio íntimo en donde el hombre, y en general toda su familia, ejerce relaciones de poder sobre la mujer y esta sobre sus hijos (microfísica del poder). En tal sentido, "sería difícil negar que la familia ha sido, si no el mayor, al menos uno de los más importantes sitios de opresión de las mujeres. Existen amor y cuidados en las familias. Pero también existen en ella violencia doméstica, violación marital, abuso sexual de niños, malnutrición de las niñas, desigual cuidado de la salud, desiguales oportunidades educativas, e incontables violaciones menos tangibles de la dignidad e igualdad de la persona" (Nussbaum, 2002, p. 322); y relaciones de poder externas al hogar, en el ejercicio de relaciones productivas (microfísica del poder), fundamentalmente. En uno y otro espacio la mujer asume una posición de subordinada. El juego en el espacio social rural es un juego asimétrico en las condiciones de desigualdad en las que se encuentran las mujeres. En tal sentido, en tanto no se juegue con los mismos sistemas de capitales, de disposiciones (habitus) y de estrategias, no podrá haber equidad, mientras seguramente sí habrá una sobrecarga de trabajo para la mujer, dicha sobrecarga entonces significará su explotación y la limitación plena del desarrollo de sus capacidades humanas.

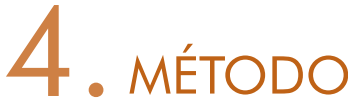

Para el desarrollo de la investigación se trabajó con la población rural, hombres y mujeres, del municipio de Lenguazaque; de allí se estableció una muestra intencional $\mathrm{O}$ por conveniencia que correspondió a 100 personas habitantes del sector rural, entre las que se encontraban, en igual número, mujeres y hombres. Para la recolección de la información se privilegió la técnica de grupos focales. Junto con la entrevista y la observación participante, se siguió un proceso metodológico tanto inductivo como deductivo.
Fue inductivo en la medida en que se trabajó con la comunidad en el desarrollo de actividades que nos permitieron ir consolidando los resultados que aquí se presentan; fue deductivo dado que se partió de fuentes teóricas que nos permitieron comprender la dinámica del sector rural y el comportamiento que en términos de relaciones se da en el interior de este; además, a través de este método realizamos procesos de generalización de los datos con el objeto de comprender, desde una perspectiva macro, la dinámica del 
sector rural, no sólo de la población objeto de estudio sino también de otras poblaciones rurales colombianas.

Seguimos el enfoque cualitativo dado que este nos permitió aproximarnos y comprender gran parte de las capacidades y necesidades de las mujeres sujeto de estudio como factores para su pleno desarrollo; si bien se presentan datos porcentuales no es su finalidad ofrecer una evaluación fría de los resultados; sí tienen como objeto mostrar con precisión el pensamiento de la población estudiada. En tal sentido, y de acuerdo con el enfoque cualitativo, se ha atendido a tres etapas del proceso de investigación de la comunidad asunto del estudio.

- Primera etapa: Visita a la comunidad, comunicación del proceso de intervención, observación participante y grabación de las experiencias en relación con sus actividades agrícolas, ganaderas y mineras.

- Segunda etapa: Desarrollo del seminario "Empresas de familia rurales, relaciones de género, relaciones de poder (la mujer en los contextos de equidad e inclusión)"; aplicación de estrategias metodológicas con el objeto de orientar el proceso de acuerdo con el método enunciado; trabajo con la comunidad haciendo uso de distintos recursos: hojas en blanco, fichas, marcadores y grabación de las discusiones generadas a partir de las reflexiones de cada una de las actividades.

- Tercera etapa: Análisis de la información, validación y consolidación de las categorías, presentación de los resultados.

\section{RESULTADOS POR CATEGORÍAS DE ESTUDIO}

1) La familia (valores y antivalores que se privilegian en la familia desde la visión de los hombres y de las mujeres del municipio de Lenguazaque, en el ejercicio de sus actividades).

\section{Gráfica 1. Valores que caracterizan a las empresas familiares rurales}

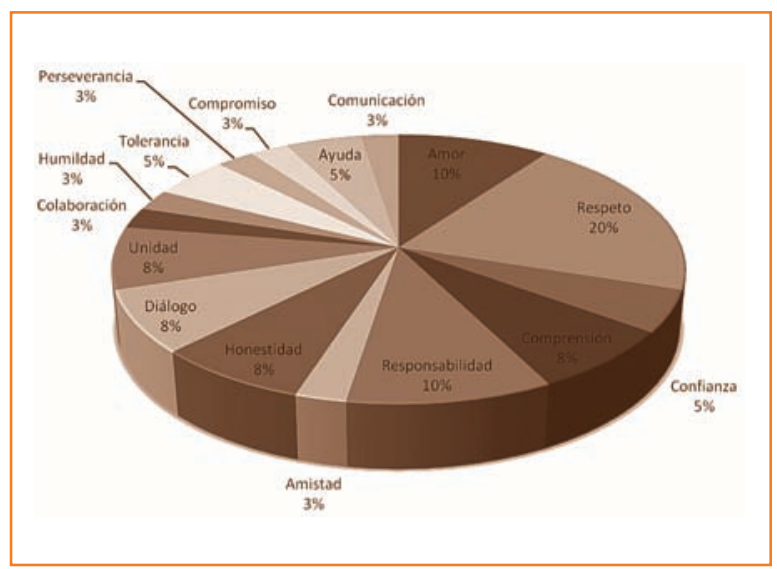

Fuente: Elaboración propia con base en los datos suministrados por la comunidad.
Según la gráfica, 20\% de las personas considera que el respeto es la base de la buena convivencia y, en consecuencia, la base para la perdurabilidad de un negocio. "Sí, yo respeto a mi familia y a mis vecinos. El diálogo siempre debe ser abierto. La unión: muchas veces cuando queda la herencia es mejor unirnos y decir cómo vamos a repartir esto y unirnos porque muchas veces, como dice el dicho: 'el que más harina tiene, más harina come'." (Argumento de una mujer campesina del municipio objeto de estudio); $10 \%$ de las respuestas corresponden a la responsabilidad y al amor; $8 \%$ a la honestidad, el diálogo y la unidad; 5\% a la ayuda, la tolerancia y la confianza, y $3 \%$ a la comunicación, el compromiso, la humildad, la colaboración y la amistad.

Entre las personas encuestadas, 14\% manifiesta que la envidia es el peor de los antivalores; el odio, el egoísmo y el irrespeto le siguen con 11\%; la indiferencia tuvo $6 \%$ de las respuestas; la irresponsabilidad, las peleas, el orgullo, la deslealtad, la ventaja, 
la mentira, la hipocresía, la intolerancia, los vicios, y la incomprensión, 3\%.

\section{Gráfica 2. Antivalores que terminan con las empresas familiares rurales.}

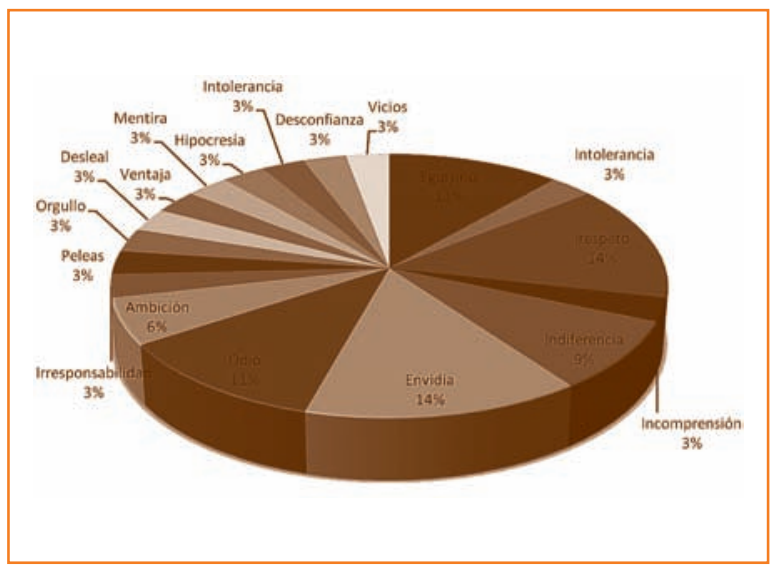

Fuente: Elaboración propia con base en los datos suministrados por la comunidad.
2) El desarrollo de las capacidades ${ }^{4}$. Atendiendo a la concepción de Martha Nusbbaum acerca del desarrollo de las capacidades, se planteó a las mujeres y a los hombres campesinos del municipio de Lenguazaque la siguiente pregunta: ¿̇e qué manera podrían las mujeres tener mayor libertad para el desarrollo de sus capacidades y aportar significativamente en el desarrollo de sí mismas, de su familia y del sector rural?; los niveles de desarrollo de la capacidad se establecieron como pleno, medio y bajo de acuerdo con el mayor o menor grado de cumplimiento. Aunque es claro que el desarrollo de las capacidades debe darse de manera plena; la mujer no se puede considerar del todo libre y en igualdad de condiciones, en este caso con relación a los hombres, si una de ellas no está satisfecha (Tabla 3).

\section{Tabla 3. Nivel de desarrollo de las capacidades de las mujeres del municipio de Lenguazaque.}

\begin{tabular}{|c|c|c|}
\hline Capacidad & Conceptualización & $\begin{array}{l}\text { Nivel de Desarrollo de la Capacidad } \\
\text { (Pleno, Medio, Bajo) }\end{array}$ \\
\hline Vida & $\begin{array}{l}\text { Ser capaces de vivir una vida humana digna, de } \\
\text { duración normal hasta su fin, sin morir prema- } \\
\text { turamente o antes de que la vida se reduzca a } \\
\text { algo que no valga la pena vivir. }\end{array}$ & $\begin{array}{l}\text { Medio } \\
\text { Las condiciones de salud dependen muchas ve- } \\
\text { ces de las capacidades económicas, por ejemplo, } \\
\text { cuando se trata de pagar medicinas costosas para } \\
\text { tratamientos de largas enfermedades. El desplaza- } \\
\text { miento y las condiciones climáticas pueden influir } \\
\text { en el estado de las vías y en la contaminación del } \\
\text { agua y del aire, esto último también puede depen- } \\
\text { der de la explotación minera. }\end{array}$ \\
\hline Salud corporal & $\begin{array}{l}\text { Gozar de buena salud, incluyendo la salud re- } \\
\text { productiva, estar adecuadamente alimentado y } \\
\text { tener una vivienda adecuada. }\end{array}$ & $\begin{array}{l}\text { Medio } \\
\text { Las mujeres aún no pueden disponer de su cuer- } \\
\text { po en cuanto a salud reproductiva se refiere. }\end{array}$ \\
\hline Integridad corporal & $\begin{array}{l}\text { Ser capaces de moverse de un lugar a otro; } \\
\text { que los límites físicos propios sean considera- } \\
\text { dos soberanos, es decir, poder estar a salvo de } \\
\text { asaltos, incluyendo violencia sexual, los abusos } \\
\text { sexuales infantiles y la violencia de género; te- } \\
\text { ner oportunidades para disfrutar de la satisfac- } \\
\text { ción sexual y de la capacidad de elección en } \\
\text { términos de reproducción. }\end{array}$ & $\begin{array}{l}\text { Medio } \\
\text { Muchas mujeres son celadas por sus esposos, ra- } \\
\text { zón por la cual no las dejan disfrutar plenamente } \\
\text { de su libertad. Algunas otras son maltratadas físi- } \\
\text { ca y psicológicamente. }\end{array}$ \\
\hline
\end{tabular}

4 El concepto de capacidades es desarrollado ampliamente por Nussbaum (2002). Entiende esta autora las capacidades humanas como "lo que las personas son realmente capaces de hacer y de ser". La perspectiva teórica de Nussbaum se sustenta en la ética Nicomaquea de Aristóteles, en la que se vislumbran claramente los principios sobre los cuales un gobierno debería trabajar con el objeto de cumplir con las exigencias de respeto hacia la "dignidad humana". 


\begin{tabular}{|c|c|c|}
\hline Capacidad & Conceptualización & $\begin{array}{l}\text { Nivel de Desarrollo de la Capacidad } \\
\text { (Pleno, Medio, Bajo) }\end{array}$ \\
\hline $\begin{array}{l}\text { Sentido, } \\
\text { imaginación y } \\
\text { pensamiento }\end{array}$ & $\begin{array}{l}\text { Ser capaces de utilizar los sentidos, de imagi- } \\
\text { nar, pensar y razonar, y de poder hacer estas } \\
\text { cosas de una manera realmente humana, es } \\
\text { decir, informada y cultivada gracias a una edu- } \\
\text { cación adecuada que incluya el alfabetismo y } \\
\text { una formación básica matemática y científica. }\end{array}$ & $\begin{array}{l}\text { Bajo } \\
\text { Muchas mujeres únicamente tienen acceso a la } \\
\text { educación primaria y muchas no la terminan, } \\
\text { excepto las mujeres jóvenes que ya han empeza- } \\
\text { do a cursar niveles medios como técnicos profe- } \\
\text { sionales o superiores universitarios. }\end{array}$ \\
\hline Emociones & $\begin{array}{l}\text { Tener vínculos afectivos con cosas y personas } \\
\text { ajenas a nosotros mismos; amar a los que nos } \\
\text { aman y nos cuidan y sentir pesar ante su au- } \\
\text { sencia; en general, amar, sentir pensar, añorar, } \\
\text { agradecer y experimentar ira justificada. Poder } \\
\text { desarrollarse emocionalmente sin las trabas } \\
\text { de los miedos y ansiedades abrumadores, ni } \\
\text { casos traumáticos de abusos o negligencias. } \\
\text { (Defender esto supone promover formas de } \\
\text { asociación humana que pueden ser demostra- } \\
\text { blemente esenciales para su desarrollo). }\end{array}$ & $\begin{array}{l}\text { Pleno } \\
\text { Por el amor que sienten hacia su familia y hacia } \\
\text { sus hijos. }\end{array}$ \\
\hline Razón práctica & $\begin{array}{l}\text { Ser capaces de formar un concepto del bien e } \\
\text { iniciar una reflexión crítica respecto a la plani- } \\
\text { ficación de la vida. }\end{array}$ & $\begin{array}{l}\text { Medio } \\
\text { Justifican el bien en los principios morales de la } \\
\text { religión que ejercen; no obstante, no hay una } \\
\text { reflexión crítica ni planificada de la vida. Esperan } \\
\text { a ver qué depara Dios cada día para cada una } \\
\text { de ellas. }\end{array}$ \\
\hline Afiliación & $\begin{array}{l}\text { Ser capaces de vivir con otros y volcados ha- } \\
\text { cia otros, reconocer y mostrar interés por otros } \\
\text { seres humanos y comprometerse en diversas } \\
\text { formas de interacción social; ser capaces de } \\
\text { imaginar la situación del otro y tener compa- } \\
\text { sión hacia esta situación; tener la capacidad } \\
\text { tanto para la justicia y la amistad. }\end{array}$ & $\begin{array}{l}\text { Bajo } \\
\text { Consideran que buscan relaciones de respeto y } \\
\text { tolerancia hacia los demás. Ayudan en la me- } \\
\text { dida de sus capacidades a quienes están en si- } \\
\text { tuaciones de desamparo o de pobreza extrema }{ }^{5} \text {. }\end{array}$ \\
\hline Otras especies & $\begin{array}{l}\text { Ser capaces de vivir interesados y en relación } \\
\text { con los animales, las plantas y el mundo de la } \\
\text { naturaleza. }\end{array}$ & $\begin{array}{l}\text { Pleno } \\
\text { Por sus condiciones de vida, es una capacidad } \\
\text { que consideran han desarrollado plenamente. } \\
\text { No obstante, reconocen que muchas veces con- } \\
\text { taminan el medio ambiente arrojando basuras } 6 \text {. }\end{array}$ \\
\hline $\begin{array}{l}\text { Capacidades para } \\
\text { jugar }\end{array}$ & $\begin{array}{l}\text { Ser capaces de reír, jugar y disfrutar de activi- } \\
\text { dades de ocio. }\end{array}$ & $\begin{array}{l}\text { Bajo } \\
\text { No tienen oportunidades para jugar y disfrutar } \\
\text { en relaciones sociales junto a otras mujeres } u \\
\text { hombres }^{7} \text {. }\end{array}$ \\
\hline
\end{tabular}

5 "No se nos facilita confiar en las demás personas debido a la experiencia que se ha tenido con otras personas, que de pronto le prestó un dinero se lo pagó en la fecha establecida pero después fue por más y ya no se lo pagó, entonces muchas veces es difícil confiar en las demás personas, mas si tenemos en cuenta que tenemos diferentes tipos de personalidad entonces es difícil uno conseguir una persona que se acople a nuestros gustos. Uno siempre conoce por mucho tiempo a una persona pero así se conviva con ella no siempre se termina de conocer., hay actitudes en ella que de pronto llegas a desconocer en algún momento. No obstante, es importante confiar en las personas porque si no confinamos en ellas, cómo vamos a llevar a una sociedad a buen término. Nosotros tenemos la tendencia que cuando conocemos a una persona la juzgamos y eso es lo que no nos deja tener confianza hacia esa persona (Conclusión de un grupo de mujeres y hombres campesinos del municipio de Lenguazaque).

6 Frente a la pregunta planteada a un grupo de campesinos (hombres y mujeres) del municipio de Lenguazaque, relativa al reciclaje de los residuos, respondieron que: "Estamos seleccionando pero nos falta apoyo, hemos estado almacenando y no nos vienen a recolectar, entonces usted se acumula de basura, entonces cómo hacer. Eso falta apoyo del gobierno. Hay cosas que se pueden utilizar como abono pero otras no". 


\begin{tabular}{|c|c|c|}
\hline Capacidad & Conceptualización & $\begin{array}{l}\text { Nivel de Desarrollo de la Capacidad } \\
\text { (Pleno, Medio, Bajo) }\end{array}$ \\
\hline $\begin{array}{l}\text { Control sobre el } \\
\text { entorno de cada uno }\end{array}$ & $\begin{array}{l}\text { Político: participación y decisión. } \\
\text { Material: Ser capaces de poseer propiedades } \\
\text { (tanto tierras como bienes muebles) no solo de } \\
\text { manera formal, sino también en términos de } \\
\text { una oportunidad real; tener derechos sobre la } \\
\text { propiedad en base de igualdad con otros. }\end{array}$ & $\begin{array}{l}\text { Bajo } \\
\text { Si bien muchas mujeres como las madres cabe- } \\
\text { za de familia poseen propiedades, muchas las } \\
\text { comparten con sus esposos, siendo ellos quienes } \\
\text { las administran. } \\
\text { Aunque las mujeres tomen decisiones políticas } \\
\text { en el momento de elegir un candidato, son muy } \\
\text { pocas las que consideran que tienen participa- } \\
\text { ción en la toma de decisiones fundamentales }\end{array}$ \\
\hline
\end{tabular}

Fuente: Elaboración propia con base en las entrevistas hechas a las mujeres de Lenguazaque, vereda Faracía y con base en el listado de capacidades que ofrece Nussbaum (2002).

De la tabla se puede establecer que de acuerdo con las mujeres entrevistadas, cuatro capacidades han desarrollado medianamente (vida, salud corporal, integridad corporal, razón práctica); consideran que solo han alcanzado dos capacidades (emociones y otras especies); y en un nivel bajo de desarrollo encontramos: sentido, imaginación y pensamiento, capacidad para jugar, y control sobre el entorno de cada una. Ello implica un alto grado de dependencia de las mujeres para la toma de decisiones, falta de libertad para disponer de su tiempo libre en actividades como el juego, el deporte, y el disfrute con sus amigas fuera del hogar; insuficientes oportunidades para participar en decisiones políticas, laborales y de tenencia de propiedades, excepto si son mujeres cabeza de familia o solteras, aunque muchas aún dependen de sus padres y, algunas otras, de sus hermanos hombres.

3) El fondo económico familiar. Para determinar esta categoría se trabajó con grupos de hombres y de mujeres con el objeto de establecer dos interrogantes: ¿̇De qué actividades se originan los ingresos?; y ¿̇quiénes son los que más contribuyen en el interior del hogar? Los resultados fueron:

\section{Gráfica 3. Actividades de las cuales provienen los recursos.}

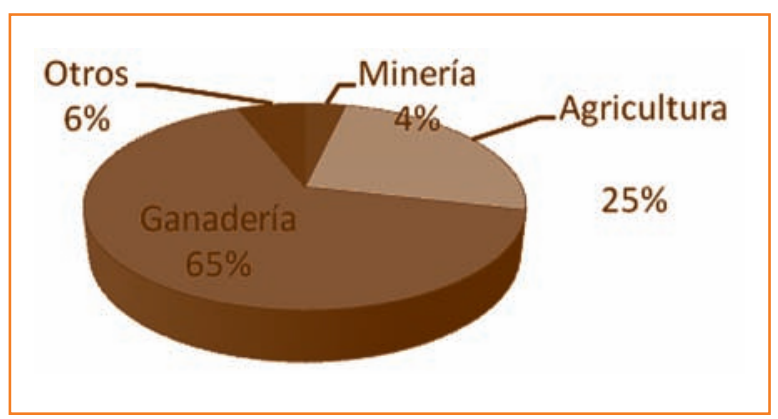

Fuente: Elaboración propia con base en los datos suministrados por la comunidad.

De la gráfica podemos determinar que $65 \%$ de los habitantes rurales del municipio de Lenguazaque obtienen sus ingresos de la

7 "Las mujeres no tenemos tiempo para nosotras mismas por estar dedicadas al hogar, a los hijos, y no tenemos la oportunidad de pasear, de divertirnos de la misma manera como lo hacen nuestros esposos" (mujer campesina del municipio de Lenguazaque).

8 "Una de las maneras es apoyarla de manera confiable y brindarle oportunidades de liderazgo, participando en otras actividades. De otra parte, el diálogo, llegar a un acuerdo, conocer sus gustos, sus debilidades y brindarle las oportunidades para que pueda gestionar un proyecto. Hoy en día se trabaja mucho la parte del machismo, si nos ponemos en los zapatos de las mujeres podemos decir que ellas también tienen las mismas capacidades que nosotros, como varones tenemos; muchas veces nosotros somos quienes administramos el dinero, entonces, pues yo creo que es algo erróneo porque las mujeres también tienen las capacidades para administrar" (Hombre campesino del municipio de Lenguazaque). 
ganadería, mientras que $25 \%$ proviene de la agricultura; otras actividades como la minería ocupan $6 \%$ y $4 \%$, respectivamente. Es importante señalar que son las mujeres quienes desarrollan las actividades agrícolas y ganaderas.

\section{Gráfica 4. ¿QQuién aporta más a la economía del hogar?}

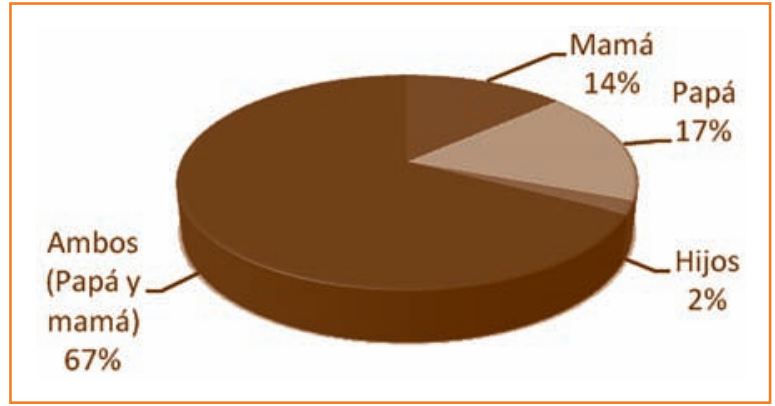

Fuente: Elaboración propia con base en los datos suministrados por la comunidad.
De acuerdo con la gráfica, $67 \%$ considera que la contribución económica depende tanto del hombre como de la mujer; $14 \%$ responde que es la mujer la que más contribuye; $17 \%$ considera que es el hombre, y sólo $2 \%$ responde que los hijos son quienes más contribuyen a la economía del hogar. No obstante, si atendemos a la gráfica anterior (gráfica 3), al ser las mujeres quienes se dedican a las actividades ganaderas y agrícolas, son ellas quienes más aportan a la economía del hogar, solo que son los hombres quienes reciben y administran el dinero.

4) Las relaciones de género, relaciones de poder. Esta categoría se determinó a partir de la información compilada en los distintos encuentros con la comunidad. De allí se pudo diseñar una matriz que integra las perspectivas con relación al poder que, desde distintas perspectivas teóricas, tratan tanto Foucault como Bourdieu.

Tabla 4. Relaciones de género, relaciones de poder.

\begin{tabular}{|c|c|c|c|c|}
\hline \multirow[t]{3}{*}{$\begin{array}{l}\text { Sujetos } \\
\text { Actuantes }\end{array}$} & \multirow[t]{3}{*}{$\begin{array}{c}\text { Habitus } \\
\text { (Disposiciones) }\end{array}$} & \multicolumn{3}{|c|}{ Lucha de Fuerzas y Tomas de Posición } \\
\hline & & \multicolumn{2}{|c|}{$\begin{array}{l}\text { Campo de fuerzas internas (la familia) } \\
\text { (microfísica del poder) }\end{array}$} & $\begin{array}{l}\text { Fuerzas externas (sistema de } \\
\text { capitales: capital simbólico vs. } \\
\text { capital económico) } \\
\text { (macrofísica del poder) }\end{array}$ \\
\hline & & Horizontales & Verticales & Espacio social rural \\
\hline $\begin{array}{l}\text { Mujeres y hom- } \\
\text { bres campesinas } \\
\text { y campesinos del } \\
\text { municipio de Len- } \\
\text { guazaque, Cundi- } \\
\text { namerca }\end{array}$ & $\begin{array}{l}\text { Mujeres campesinas, } \\
\text { madres, hermanas, es- } \\
\text { posas, en edades entre } \\
15 \text { y } 60 \text { años; dedi- } \\
\text { cadas a la ganadería } \\
\text { como principal ingreso } \\
\text { económico y a la agri- } \\
\text { cultura como su segun- } \\
\text { do renglón. Constituyen } \\
\text { las llamadas empresas } \\
\text { de familia rurales. }\end{array}$ & $\begin{array}{l}\text { Las relaciones de } \\
\text { poder internas en la } \\
\text { familia de carácter } \\
\text { horizontal práctica- } \\
\text { mente son nulas, } \\
\text { pues están plena- } \\
\text { mente jerarquiza- } \\
\text { das. Escasamente se } \\
\text { presentan con algu- } \\
\text { no de los hermanos } \\
\text { cuando no existen } \\
\text { relaciones tensas } \\
\text { por el pasado fami- } \\
\text { liar, debido a la he- } \\
\text { rencia, por ejemplo. }\end{array}$ & $\begin{array}{l}\text { Las relaciones son } \\
\text { jerárquicas. El pa- } \\
\text { dre ocupa la parte } \\
\text { superior de la pi- } \\
\text { rámide; le sigue la } \\
\text { madre y continúan } \\
\text { los hijos. Cuando } \\
\text { no hay esposo, la } \\
\text { madre ocupa la } \\
\text { escala más alta } \\
\text { que termina sien- } \\
\text { do ocupada por el } \\
\text { hijo hombre mayor. } \\
\text { Cuando no tienen } \\
\text { hijos varones, mu- } \\
\text { chas de ellas termi- } \\
\text { nan dependiendo } \\
\text { de sus hermanos } \\
\text { hombres, para la } \\
\text { toma de decisiones. }\end{array}$ & $\begin{array}{l}\text { - El poder que ejerce la socie- } \\
\text { dad sobre la mujer es el resul- } \\
\text { tado de la visión patriarcal que } \\
\text { se ha heredado de generación } \\
\text { en generación y que constituye } \\
\text { la visión del mundo del hombre } \\
\text { latinoamericano. En el contexto } \\
\text { rural tal visión del mundo está } \\
\text { más enraizada en el imaginario } \\
\text { de los campesinos. } \\
\text { - Las mujeres tienen menos opor- } \\
\text { tunidades de desarrollo, sobre } \\
\text { todo en lo relacionado con la } \\
\text { formación profesional universi- } \\
\text { taria. Muchas de ellas terminan } \\
\text { haciendo cursos de capacitación } \\
\text { de corta duración o carreras } \\
\text { técnicas, también de corta du- } \\
\text { ración. }\end{array}$ \\
\hline
\end{tabular}




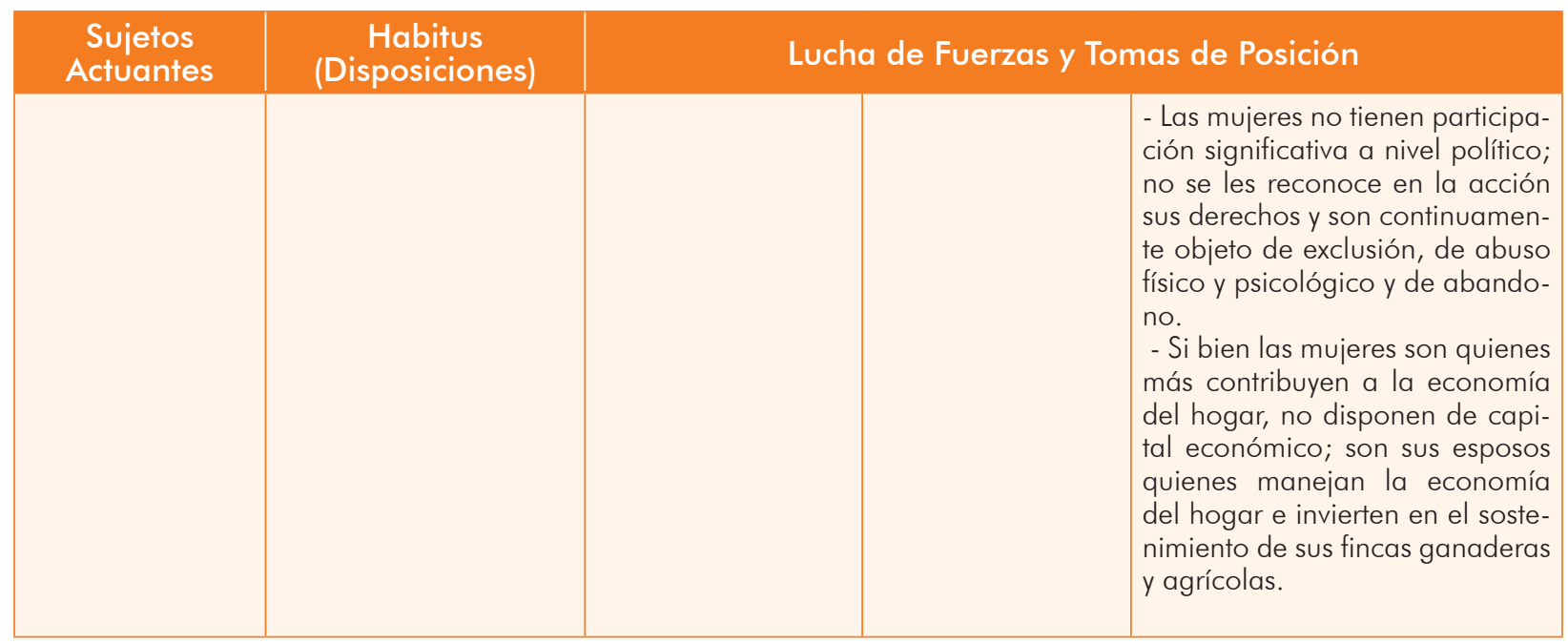

Tabla 5. Las estrategias del poder?.

\begin{tabular}{|c|c|c|c|c|}
\hline $\begin{array}{l}\text { Sujetos } \\
\text { actuantes }\end{array}$ & $\begin{array}{l}\text { Sistema de } \\
\text { diferenciaciones }\end{array}$ & $\begin{array}{l}\text { Objetivos } \\
\text { perseguidos }\end{array}$ & $\begin{array}{l}\text { Los medios que } \\
\text { dan origen a las } \\
\text { relaciones de } \\
\text { poder }\end{array}$ & $\begin{array}{l}\text { Formas de } \\
\text { institucionalización }\end{array}$ \\
\hline $\begin{array}{l}\text { Mujeres y hom- } \\
\text { bres campesinas } \\
\text { y campesinos del } \\
\text { municipio de Len- } \\
\text { guazaque, Cundi- } \\
\text { namerca }\end{array}$ & $\begin{array}{l}\text { - Diferencias estableci- } \\
\text { das en el seno de la fa- } \\
\text { milia como reproductora } \\
\text { de la sociedad. Diferen- } \\
\text { cias establecidas por el } \\
\text { privilegio que nuestra } \\
\text { cultura les brinda a los } \\
\text { hombres, incluyendo, } \\
\text { muchas veces, las mis- } \\
\text { mas mujeres. Diferencias } \\
\text { económicas: los hom- } \\
\text { bres adquieren mayor } \\
\text { estatus al disponer del } \\
\text { capital económico. }\end{array}$ & $\begin{array}{l}\text { A la mujer campesina } \\
\text { desde niña se le pre- } \\
\text { para para ser madre } \\
\text { y esposa. Al hombre, } \\
\text { desde niño, se le } \\
\text { prepara para asumir } \\
\text { retos y tomar decisio- } \\
\text { nes. }\end{array}$ & $\begin{array}{l}\text { - La educación. } \\
\text { - El sistema de valores. } \\
\text { - Los sistemas de ca- } \\
\text { pitales, fundamental- } \\
\text { mente el económico y } \\
\text { el simbólico. }\end{array}$ & $\begin{array}{l}\text { El Estado, la familia, la } \\
\text { Iglesia. }\end{array}$ \\
\hline
\end{tabular}

Fuente: Elaboración propia con base en Bourdieu.

De acuerdo con las Tablas 4 y 5 acerca de las relaciones de género y las estrategias de poder, se da cuenta de al menos dos dimensiones que el PNUD ha considerado para medir los índices de desigualdad de género: el empoderamiento de la mujer en la toma de decisiones y su falta de participación activa y no excluyente del mercado laboral; podríamos considerar, no obstante, una tercera dimensión relativa a la educación (que pudiera estar implícita en el componente del mercado laboral), dado que las mujeres rurales del estudio que nos ocupa tienen poco, si no escaso y nulo, acceso a

9 Se puede llamar estrategia de poder a la totalidad de los medios que se ponen en operación para aplicar el poder efectivamente o para mantenerlo (Foucault: 1991). 
la educación. Aunque aquí no se establece el índice de desigualdad de género (IDG) -propuesta que se está trabajando y que dará continuidad a este estudio- sí se puede ya vislumbrar la falta de libertad de la mujer, que se refleja en su falta de bienestar y en la imposibilidad de desarrollar plenamente sus capacidades.

\section{CONCLUSIONES}

Las empresas de familia rurales apenas empiezan a ser importantes para la economía del país; de potenciarse su desarrollo, habría una clara disminución de la pobreza en el sector rural. Para tal propósito los gobiernos deben proveer la infraesteructura necesaria y suficiente para que este desarrollo sea posible, lo cual implica que no se debe pensar únicamente en términos económicos,sino, especialmente, llevar a cada uno de los habitantes rurales al desarrollo pleno de sus capacidades con el propósito de ofrecerles una vida digna.

Las empresas de familia rurales se caracterizan por el cultivo permanente de valores y de antivalores que conducen $\mathrm{o}$ bien a la permanencia y perdurabilidad de la empresa, o a su desaparición. En muchas familias cada integrante piensa en su propio beneficio, razón por la cual la sucesión se convierte en un elemento que taja de una sola pasada el antes y el después de muchas empresas familiares rurales, así después esté marcado con relaciones irreconciliables entre sus miembros.

Las mujer campesina si bien tiene una amplia participación en el bienestar de su familia, no cuenta con el apoyo esencial ni de los miembros que constituyen su núcleo familiar ni de los entes gubernamentales. Muchas mujeres encuentran dentro de su propio núcleo familiar, opresión, excluisión, falta de apoyo, maltrato físico, psicológico y abuso sexual. A la mujer no se le reconocen económicamente sus labores como gestoras y transformadoras dinámicas del desarrollo agrícola y ganadero de su familia y, en consecuencia, del desarrollo económico de su comunidad, como tampoco se les reconoce como amas de casa.

Las mujeres a nivel social y político no tienen la misma participación que los hombres. La sociedad misma las trata como desiguales y carentes de capacidades para decidir y tomar decisiones. No hay mujeres, en la población objeto de estudio, ocupando cargos de dirección ni de administración. La equidad y la inclusión de la mujer en todas las actividades de la vida familiar, social, política, económica y religiosa, pudiera ser una solución fundamental para la erradicación de la pobreza y su consecuencia desvastadora, el hambre.

Las relaciones de poder, entendido este como estrategia implícita o explícita de cualquier tipo de relación, se debe considerar ante todo como acción; este aspecto le confiere el carácter dinámico que se establece entre los sujetos actuantes, quienes insertos en un entorno social comportan una ideología y una visión del mundo que complejiza las relaciones entre unos y otros. Pudiera afirmarse, en consecuencia, que la situación de la mujer en general y de la mujer rural, en particular, obedece a un tipo de poder instaurado en el fenómeno patriarcal que ha perdurado hasta hoy en nuestros contextos culturales; por tales razones y de acuerdo con Bourdieu, el poder y las relaciones que a partir de este se ejercen no pueden considerarse de manera aislada. En tal sentido tendríamos que considerar el sistema de los campos dentro del espacio social junto con la dinámica que cumplen los sistemas de disposiciones (habitus) y de capitales (cultural, económico y simbólico, principalmente). 


\section{BIBLIOGRAFÍA}

Agricultura y desarrollo rural sostenibles (ADRS) sumario de política. Las ADRS y las empresas rurales (2007). Documento en línea: ftp//ftp. fao.org/docrep/fao/010/ai120s/ail29s.pdf (Recuperado el 12 de octubre de 2012).

Bourdieu, P. (2003). Las estructuras sociales de la economía. Kauf, T. (trad.) Barcelona: Anagrama.

FAO (201 1). "El estado mundial de la agricultura y la alimentación. Las mujeres en la agricultura. Cerrar la brecha del género en aras del desarrollo". http://www.fao.org/docrep/013/ i2050s/i2050s.pdf (Recuperado el 19 de octubre de 2012)

Farahq, M.A. y Pérez, E. (2004). "Mujeres rurales y nueva ruralidad en Colombia". Documento en línea en: http://mww.javeriana.edu.co/ier/ recursos_user/documentos/revistas 51/137_160. pdf (Recuperado el 12 de octubre de 2011).

Foucault, M. (1991). El sujeto y el poder. Precedido por tiempo y espacio en el discurso de Michel Foucault. Gómez, C. y Ochoa, J. (trad.) Bogotá: Carpe Diem Ediciones.

Informe sobre el desarrollo humano. Programa de las Naciones Unidas para el Desarrollo (PNUD), (2011). Documento en línea: http://hdr.undp. org/es/ (Recuperado el 20 de enero de 2011).

Informe sobre el desarrollo humano. Programa de las Naciones Unidas para el Desarrollo (PNUD), (2011). "El índice de desigualdad de género". Documento en línea: http://hdr. undp.org/es/estadisticas/idg/ (Recuperado el 7 de junio de 2012).

Nussbaum, M.C. (2002). Las mujeres y el desarrollo humano. Bernet, R. (trad.), Barcelona: Herder.

Wills Obregón, M.E. (2007). Inclusión sin representación. La irrupción política de las mujeres en Colombia 1970-2000. Bogotá: Norma.
${ }^{66}$ Las empresas de familia

rurales se caracterizan por el

cultivo permanente de valores

$y$ de antivalores que conducen

o bien a la permanencia

y perdurabilidad de la

empresa, o a su desaparición.

En muchas familias cada

integrante piensa en su propio

beneficio, razón por la cual

la sucesión se convierte en

un elemento que taja de una

sola pasada el antes y el

después de muchas empresas

familiares rurales, asi después

esté marcado con relaciones

irreconciliables entre

,

sus miembros. 
